\title{
CULTURAL IDENTITY CONSTRUCTION IN PAKISTANI ANIMATION
}

\author{
Madiha Jamil \\ Motion Graphics Lecturer, Dar Al-Hekma University, Saudi Arabia, \\ madiha.jamil1@gmail.com
}

\begin{abstract}
The customs, culture and traditions of the people of a country are representative of the history, faith, language and environment of that country. Similarly, the cultural patterns of Pakistan speak of its rich cultural heritage and traditions. Pakistan's popular culture is not only the likeness of the present but also heavily depends on the past. Pakistan's Mughal architecture, cuisine, textiles, television programs, music etc. are some forms that make up its pop culture. The growth and increased range of available local and foreign media content has raised numerous questions as to the impact and effects it brings towards Pakistani culture. As a mature International industry and rapidly growing local one, animation films have taken a role in introducing the cultural characteristics of various nations and backgrounds. Animation offers a contested site for identity formation through story-telling, which provides wide audiences with the resources for narrativecreation and imagined communities that can foster collective identities. This article attempts to illuminate how the medium of animation articulates the Cultural Identity of Pakistan, through the national history. For this purpose, it analyzes two local animations: Unicorn Black's Burka Avenger and Teen Bahadur by Waadi Animation and SOC Films. These works are examined, particularly by looking at the gendered, outfitted, linguistic and racial representations. This research intends to dive deeper into designing of characters i-e protagonist, antagonist and supporting characters. The way pre-conceived notions of cultural identities have been represented in the animations. This study will aid in better understanding the complexities of cultural identity reflected in popular media.
\end{abstract}

Keywords: Animation, 3D technology, cartoon, cultural identity, national identity.

\section{INTRODUCTION}

Animations in the form of cartoons, anime and animated feature films are popular forms of entertainment and widely used in various fields such as advertisement, entertainment, education and science. ${ }^{1}$

Our literature has always played an important role in our lives, especially from the cultural aspect, since it is rich with local references, educational messages and socio-cultural awareness to be imparted to the people in our society.

\footnotetext{
${ }^{1}$ Report:_Promoting_Socio_Cultural_Values_Through_Storytelling_Using_Animation_and_Game_Based_Edutainment Software,_Nor_Azan_Mat_Zin_and_Nur_Yuhanis_Mohd_Nasir,_Universiti_Kebangsaan_Malaysia
} 
Now a days our local children are more familiar with western literature, stories, poems, cartoons, folk tales, animated films as presented by companies like Disney, Pixar, DreamWorks, Hollywood etc. such as ${ }^{2}$ Snow White, Sleeping Beauty, Cinderella, Tintin, Lorax etc. The reason behind such a familiarity with other's culture is the mass production and aggressive distribution and marketing of their artworks using characters, environments, signs, symbols, metaphors, colors, avatars, icons and motives to depict the visuals in a story according to their own socio-cultural themes. Therefore, to promote local literature with our own eastern themes to our local audience, a more attractive way is needed, one of which is with the help of creative writers and multimedia artists providing storylines for animated films and understanding the role of semiotics in the depiction of our traditional and local design elements.

The need is to carry out the research to develop entertainment with contents from the Pakistani literature or culture to help promote society's socio-cultural values to the coming up generations. Animation and digital storytelling can help viewers visualize our traditions, cultural events, local terms and elements besides presenting content in an interesting, lively and dynamic manner.

Usually it is observed that children and young generation are animation-enthusiasts and easily drawn into watching animated content programs. Folk stories, short stories and poems which were previously presented verbally or in printed forms that is published material, can now be delivered and shared with people in a much more interesting and mesmerizing way using today's animation techniques. ${ }^{3}$

Multimedia-based content will create a new dimension to revive the traditional literature and showing up our heritage, cultural events and props, social interests, lifestyle and local architecture. Along with this, good values could reach them if the content of the animated films is designed to fit them.

\subsection{Rationale}

The research aims to look at how Pakistani culture is portrayed in local animations.

\subsection{Objectives}

1. To find the specific representation of culture in Pakistani animation.

2. To find if these cultural representations are found in all Pakistani animations.

3. To look into the thought process behind each character and environment design.

\subsection{Scope}

The research does not touch upon the impact that Pakistani animation has on its viewers. It also does not explore the popularity of animations.

\subsection{Limitations}

In Pakistan, most of the animation work that is found in the market is so far for commercial purposes. This is to say that the story lines have a purpose to ultimately sell the product. Therefore, this research focuses on two non-commercial animations - Burka Avenger, Teen Bahadur.

\section{METHODOLOGY}

\subsection{Study Design}

This is a content analysis of two non-commercial Pakistani animations.

\section{ANALYSIS}

\subsection{Television Analysis (Burka Avenger)}

\subsubsection{Brief}

Title of Animation: Burka Avenger

Name of Channel: Geo Tez T.V / Nickelodeon Pakistan

Duration (MIN): 23 MIN

\footnotetext{
${ }^{2} \mathrm{http}: / /$ theladiesfinger.com/the-burqa-joins-the-league-of-cape-and-cowl/

${ }^{3}$ Report:_Promoting_Socio_Cultural_Values_Through_Storytelling_Using_Animation_and_Game_Based

Edutainment_Software,_Nor_Azan_Mat_Zin_and_Nur_Yuhanis_Mohd_Nasir,_Universiti_Kebangsaan_Malaysia.
} 
Time slot: The show ended in 2015. Only four seasons were aired.

Target audience: Youth and Children

Subject: Social/ Cultural/ Children

Language: Urdu

\subsubsection{Justification of Title}

The protagonist of the show is Jiya, an inspirational school teacher whose alter ego is the super-heroine Burka Avenger. She uses Burka as a disguise to conceal her true identity. Her use of books and pens as weapons is symbolic on many levels. The Burka Avenger fights for Justice, Peace and Education for all.

\subsubsection{Synopsis}

Burka Avenger, the TV show, is about a young school teacher Jiya in a small town Halwapur in Pakistan whose secret identity as a masked vigilante who helps ensure the town's safety, progress and most importantly, the education of its female children. The other four main characters are Kabadi Jaan, Ashu, Immu and Mooli. The two main Antagonist in the show are Baba Bandook (a sort of fraudulent faith healer) and Vadero Pajero (a sort of greedy feudal landlord) who are always planning new ways to spread terror and take over control of Halwapur city.

"Smart, colorful and provocative, this Pakistani-produced television program about a super-heroine sends a clear message about female empowerment that has the potential to affect an entire generation." - Peabody.

\subsubsection{Treatment}

The show features the use of humor and stylistic musical themes except this time; the music is based on traditional Punjabi $\mathrm{dhol}^{4}$ beats also featuring guest appearances and original songs from some of the biggest musical acts from across South Asia (including Ali Zafar, Haroon, Ali Azmat, Josh and many others). The traditional music pulls this show out of the typical western style, exploring a wide new take on traditional ideas. The characters overall are very stylized and exaggerated with big heads and eyes, which makes them appealing yet funny.

\subsubsection{Locations}

All over Halwapur City, Mainly outdoors.

\subsubsection{Character Analysis of Jiya}

Name of the Character: Jiya/ burka avenger

Gender: Female

Age group: $24-27$

Marital status: Unmarried

Class: Middle

Occupation: Teacher/ Savior

Does he/she have children? No

\section{a) Depiction}

To the locals, she is known simply as the inspirational school teacher Jiya, but whenever evil is afoot, she takes on her alter identity, Burka Avenger. She lost her parents in a tragic accident and later adopted by Kabadi Jaan (her foster father in the show). She uses Takht Kabaddi (a secret ancient mystic martial art where books and pens are primarily used as weapons in conjunction with a variety of advanced acrobatic moves) to defeat the bad guys. As the Burka Avenger, she uses the Burka as a disguise to conceal her true identity like super heroes do. No one knows the truth except for her foster father.

\section{b) Cultural Representation}

As Jiya, she is an inspiring school teacher and hence designed in a way that it can be related to the government school teachers in Pakistan. She has whitish complexion with big eyes, long braided hair. She wears pink Kurta with tight Churi pajama with Dupatta and does not cover her head in daily life. Choice of

\footnotetext{
${ }^{4}$ Local Drum
} 
pink color for Jiya's dress symbolizes with the feminine side of her.

Wherever as Burka Avenger, Jiya uses Burka as a disguise to hide her identity. Burka or Niqab is a dress that Muslim women wear to cover themselves. Some people also take it as a symbol of women's oppression, an item of clothing that limits women and forces them to hide. Although most of the women in Pakistan do not wear burka, but prefer to wear chaddar ${ }^{5}$. Burka Avenger has let its protagonist take ownership of the burqa. It is no longer a symbol of the oppressed woman (if you feel that way about a burqa), because it is now a part of her strong, motivated alter ego. Jiya is an educated young middle-class woman who wears a regular Shalwar Kameez ${ }^{6}$. To hide her identity, she uses the most ubiquitous of items, because if a woman is looking to hide in plain sight in urban Pakistan's crowded streets, what better to use than the burqa? Burka Avenger could blend seamlessly into any bazaar dressed the way she is. Looking at Burka Avenger's outfit on a larger scale, in a pop culture environment currently sated with hyper sexual female superheroes dressed in straight up body condom pervert suits like that of Black Widow or Cat woman, burqa is an admirable sartorial choice on part of the show's creators.

The personality of this female vigilante has immense character strength. She is inspirational, social, helpful, attractive, active and honest.

She is shown with high values of courage, sense of justice, equality as well as progressiveness.

\subsubsection{Character Analysis of Baba Bandook}

Name of the Character: Baba Bandook

Gender: Male

Age group: 40 - 45

Marital status: Unmarried

Class: Middle

Occupation: Fake magician

Does he have children? NO

a) Depiction

Baba Bandook as known as Jaali Jadoogar (fake magician) is the main villain of the story. He thirsts for power and wealth and is always planning new ways to spread terror and take over control of Halwapur city. Most of his time is spent in planning the destruction of the Burka Avenger. Baba Bandook and his henchmen are also mercenaries for hire.

b) Cultural Representation

Baba Bandook is a middle height, bony man dressed in extravagant clothing, always seen wearing a gold, ruby-eyed, cobra headed turban. Baba Bandook has a rough pointed beard, and a thick mustache, as well as black eyeliner. He was supposed to be designed as ugly. Baba Bandook wears black robe that reach the ground with tight sleeves and with a pearl locket. Baba Bandook is a conventional depiction of local magicians or PEER (faith healers) found in rural areas of Pakistan. Having long beard and wearing long dress called "Chola" which covers the full body with a turban and number of long necklaces is a stereotypical demonstration of PEER in Pakistan. Normally the Peer wear green chola as green is associated with religion Islam but in the show since Baba Bandook is a fake magician he is wearing black to represent the evil /fake aspect. The golden snake on his turban represents how dangerous and harming he can be. Baba Bandook also displays narcissistic tendencies, his most obvious ones being his obsessive desire for power and sense of entitlement and to kill Burka Avenger.

He has a selfish, violent, greedy, leader, rebellious and reckless personality.

His values are courage, competitive and he never give up.

\subsubsection{Relationship of Characters with each other}

Burka Avenger and Baba Bandook are two main protagonist and antagonist of the show. Baba Bandook who is thirsty for wealth and power, always try to create complications and terror for the people of Halwapur along with his henchmen, whereas Burka avenger is their savior. She protects the city from the machinations of

\footnotetext{
${ }^{5}$ Long piece of cloth uses to cover body from head to knee

${ }^{6}$ Shalwar Kameez is the national dress of Pakistan
} 
Baba Bandook.

\subsection{FILM ANALYSIS (3 Bahadur)}

\subsubsection{Brief}

Title: Teen bahadur

Name of the production house: Waadi Animation

Duration: 1 hr 30 min

Time of release: $22^{\text {nd }}$ May 2015

Target audience: Children and Youth

Subject: Children/ Social/ Comedy

\subsubsection{Justification of Title}

3 Bahadur is the story of three extraordinary children who rise from the most unlikely of places and save their town from the evil that plagues it. Equipped with courage and super powers, 11-year-old Amna, Saadi and Kamil battle against the odds and stand up to injustice to restore peace and harmony in their once thriving community and live a very happy life.

\subsubsection{Synopsis}

Teen Bahadur is set in a remote settlement called "Roshan bast" ", where a festival is going on. A little while later, a little girl was kidnapped by a thug named Mangu. A brave man ran after him, knocked the thug over and rescued the girl. The town's idyllic life is shattered when that petty thief Mangu makes a Faustian deal with the demonic Baba Balaam who entrusts him with a key that is supposed to be the source of all evil in the world. The town then plunges into despair and darkness and is now known as "Andher nagri" movie basically follows the story of three kids Saadi, Amna and kamil who join together after a series of injustices they have suffered at the hands of Mangu and his goons. One day they all went to the clock tower to face Mangu and his goons, where they were granted with special powers for their protection. Following different events, they use all their powers to defeat Mangu by throwing the evil key into a powerful black hole that Saadi created with all his power.

\subsubsection{Treatment}

The movie was done in 3D computer animation. The show deals with many issues and the well- developed characters portray many different personalities. Waadi Animations has engineers on its staff who understand the physics of sound and light and how these elements will affect movement in characters. The overall character design is quite realistic and less exaggerated. Although the design team tried to incorporate maximum characteristics but the western influence can still be seen clearly in 3 bahadur characters. Looking at their facial features they still remind you of characters from different western animated films i-e astro boy, cloudy with the chance of meat balls, monsters vs aliens. Strong cultural elements can also be witness, which makes them relatable to local children of Pakistan.

\subsubsection{Major Issues}

Teen Bahadur deals with many deep and mysterious secrets. Roshan Basti is divided into good and evil worlds. Different types of characters live in different places such as human resides on a place similar to earth and the evil demon is hiding in the clock tower, wants to protect the key to the evil world and local security guard, Deenu Chacha who is the guardian of the key which preserves all the good powers.

\subsubsection{Location}

\section{Roshan Basti}

\subsubsection{Character Analysis of Saadi}

Name of the Character: Saadi

Gender: Male

Age group: 11 Years

\footnotetext{
${ }^{7}$ Roshan means Light, Basti means Town

${ }^{8}$ Andhair means Dark, Nagri is another work for Town
} 
Marital status: Unmarried

Class: Middle

Occupation: Student

Does he have children? No

\section{a) Depiction}

Three friends who study in the same school, belonging to middle class struggling families, are all the apple to each of their parent's eyes. While Saadi represents the obedient, studious yet hungry to prove their worth children in our society. Saadi takes keen interest in science and experiments and spend most of his time making new machines. Later Saadi is granted with the super power of intelligence and the ability to comprehend things cleverly. While not the bravest of the three kids, Saadi is the most intelligent and the one everyone looks at to come up with a plan.

b) Cultural Representation

Saadi is designed keeping in mind that he is an obedient, thoughtful and curious kid. He should be relatable to all the kids who love to study and explore. Saadi is designed as simple 11-year-old boy wearing glasses and hair properly combed and set. Saadi is also energetic and brave, since the film has a lot of action and complex fight moves and due to technical complications all three characters can be seen in western outfit instead of traditional Shalwar kameez ${ }^{9}$.

He has an intelligent, caring, obedient, smart, justice, equality, brave and active personality.

The values he possesses are courage, sense of justice, progressiveness, competitiveness and helpfulness.

\subsubsection{Character Analysis of Amna}

Gender: Female

Age group: 11 Years

Marital status: Unmarried

Class: Middle

Occupation: Student

Does he/she have children? No

\section{a) Depiction}

Smart and sporty, Amna is always two steps ahead of boys. She is driven by a need to bring about justice and fairness. Amna embodies the powerful females who are guardians to their circle proving a female does not always need a man to protect her and sometimes she is the one protecting and taking care of the men around her. Equipped with the ability to move at extraordinary physical speed, Amna often act as a savior of the 3 bahadur. Her super powers allow her to rescue her friends in times of crisis and flee from the scenes of danger.

b) Cultural Representation

Amna is designed keeping in mind that she can be relatable to most of the school girls in Pakistan. She is not afraid of stopping anyone from wrong doing and always stand for justice. She moves fast and keeping that mind her hair is kept short, so that she won't have any trouble in doing complex action moves. Instead of wearing a top, Amna is wearing a traditional pink printed kurti, straight jeans with the scarf wrap around her neck to give her a local finish.

She has an intelligent persona. She is a leader, protective, obedient, smart, just and thrives for equality through her bravery.

The values her character possess are courage, sense of justice and progressiveness, competitive as well as helpful.

\subsubsection{Character Analysis of Kamil}

Name of the character: Kamil

\footnotetext{
${ }^{9}$ Shalwar Kameez is the national dress of Pakistan
} 
Gender: Male

Age group: 11 Years

Marital status: Unmarried

Class: Lower middle

Occupation: Student

Does he/she have children? No

\section{a) Depiction}

Kamil, is the mischievous, hyper active kid of the lot, yet cares about his friends and family in his own unique way. He is talkative, funny and love food and desserts. He has a special attachment with a street dog "Gabru" and often brings him biscuits and milk. Kamil is granted by the power of super hearing from distant places and often times inaudible sounds as well, which gives him edge on battle field. Later on Deenu chacha grants him by another super power of the ability to fly and jump up high. His cheeky sense of humor and overconfident personality results in many comic moments throughout the film.

b) Cultural Representation

Kamil is a fun kid who always wants to play in the streets. His father owns a small Dhaba ${ }^{10}$. He is designed by taking inspiration from street children in Pakistan. Kamil is always jumping, wandering around, playing with his dog and yet wearing a chappal ${ }^{11}$. Kamil can be seen in most casual clothes with rough hair and a blue cap and is the most fun character of the film.

He has a cheerful, caring, funny, smart, just, brave and a hyperactive personality.

He possesses high values of courage, sense of justice, progressiveness, competitiveness and he is very helpful.

\subsubsection{Character Analysis of Mangu}

Name of the character: Mangu

Gender: Male

Age group: Unknown

Marital status: Unmarried

Class: Lower

Occupation: Criminal

Does he/she have children? No

\section{a) Depiction}

Mangu was a petty thief or thug in the beginning of the movie, who later on makes a Faustian deal with the demon "Baba Balaam" and becomes the criminal overlord of Andher Basti. These demonic power gave him an iron fist, by which he rules the colony and doesn't spare anyone from his malicious practices. Mangu is extremely arrogant and endures power to hear everything, see everything and moves so quick that sometimes people claim to see him at different places at the same time. ${ }^{12}$

\section{b) Cultural Representation}

Mangu being the main antagonist of the movie is a long, broad, sharp featured man. In the beginning of the film, Mangu have long hair with ponytail, stubble and wears black shalwar kameez with cuffs folded upwards. His pointy eyebrows and chin gives him a more villainy look. After he endures the demonic power he hid himself in a long robe with hood to cover his body and face as he became dreadful.

He has a selfish, violent, greedy, ruthless, leader and reckless personality.

He possesses values like courage, competitiveness and he never gives up.

\footnotetext{
${ }^{10}$ Dhaba is the name given to roadside restaurants in India and Pakistan.

${ }^{11}$ Flipflops

12 http://www.3bahadurmovie.com/thugs.php
} 


\subsubsection{Relationship of Characters with each other}

Amna, Kamil and Saadi are the eleven years old, three main protagonists. They want to help people of Andhair Basti who are living under the terror of Mangu from a very long time. Mangu is a criminal overlord who wants to rule Andhair Basti, owns demonic powers and never spares anyone who try to come in his way. He has a gang of thugs who act as his spies and run his various criminal activities.

\section{CONCLUSION}

This research aimed to achieve certain objectives that are mentioned earlier. The content analysis done has brought to light certain aspects that the research wished to explore. This research helped in analyzing how Pakistan is developing its cultural identity through Animation. Considering the fact that animation is relatively a new field in Pakistan, the artists or designers try to incorporate as many cultural elements as possible, still western influence can be seen in their visual style. The reason behind so much influence is probably due to the internal cultural conflicts between defined identities of Sindhis, Punjabis, Balochis and so on, that render being called just a Pakistani is somewhat complicated. This cultural complexity needs to be overcome to define our own style just as Iran, Japan and Middle East.

In most of the animation projects, culture is reflected through different means for examples; through objectives, dress codes, locations and even language. The most successful ventures of cultural representation are by Disney since 1923, they have been releasing feature films that have showcased a number of cultures from around the world. This would include, but not limited to Pocahontas which centers on Native Americans, Aladdin which depicts the Arabs and Mulan which gives us glimpses into the Chinese culture and traditions.

Since everything is globalized it becomes easier to exchange the information and cultural values across borders. People would like to see more cultural content in animation, especially for their children. The minds of the children are moldable and vulnerable to the kind of nurturing they are exposed to; if quality cultural content is developed for them, with role models they can look up to and identify with, it would lead to a stronger future of Pakistan. The level of cultural content is steadily improving, with graphic novels on Urdu heroes like Burqa Avenger and Teen Bahadur animated feature might change the game field quite a bit. There are a lot of possibilities to celebrate our culture more. Animation can become a powerful tool through which the culture and identity of a nation can be shared.

\section{REFERENCE LIST}

Asha Jhina, 2011. Representations of culture in Japanese animation. India

Kaori Yoshida, 2011. National Identity (Re) Construction in Japanese and American Animated Film. Associate Professor, College of Asia-Pacific Studies. Electronic journal of contemporary Japanese studies. Article 5 in 2011.

Aysha Faseeh, 2014. To what extent can Pakistan's Culture be promoted through Digital Art and Animation for the Pakistani nation? Karachi: Indus Valley School of Art and Architecture.

Madiha Jamil and Saleha Alvi, 2013. 3D Animated Short film "Guddu ki Guddi" (Entertainment through animation in Pakistan). Lahore: National College of Arts.

Yusra Saleem, 2011. Loss of Cultural Identity. Karachi: Pakistan Today.

Mohd Amir Mat Omar \& MD Sidin Ahmad Ishak, 2011. Understanding Culture Through Animation: From the World to Malaysia. Journal Pengajian Media Malaysia, Malaysian Journal of Media Studies. Vol. 13, No. 2, 2011, Pages 1-9.

Timothy Graham Jones, Animating Community: Reflexivity and Identity in Indian Animation Production Culture. University of East Anglia. School of Art, Media and American Studies, September, 2014.

Saad Afridi, Jun 11, 2011. Animation Industry of Pakistan. 2016.20 August

https://www.scribd.com/document/57594976/Animation-Industry-of-Pakistan

Burka Avenger. 2016. 20 August www.burkaavenger.com

Teen Bahadur. 2016. 22 August http://www.3bahadurmovie.com/heroes.php 
Thee Mad Queen, July 15, 2015. Movie review: 3 bahadur and birth of superheroes in Pakistan.

2016. 22 August https://theemadqueen.wordpress.com/2015/07/15/movie-review-3-bahadur-and-birth-ofsuperheroes-in-pakistan/

Aseem Kulkarni, 12 April 2016. There is a new country taking animation by storm, and it is an unlikely one: Pakistan. 2016. 23 August http://www.catchnews.com/culture-news/there-s-a-new-country-takinganimation-by-storm-and-it-s-an-unlikely-one-pakistan-1460444708.html/3 